\title{
Perception and practice of Ramadan fasting among patients with type I diabetes mellitus in the view of the practical guidelines
}

\author{
Inass Taha ${ }^{1 *}$, Intessar Sultan ${ }^{2}$, Abdullah Al-Harby ${ }^{3}$, Randa Alharizi ${ }^{2}$ and Lama Ghandoura ${ }^{2}$ \\ ${ }^{1}$ Department of Medicine, Taibah University, Madinah, Saudi Arabia. \\ ${ }^{2}$ Department of Medicine, Ibn Sina National College for Medical Science, Jeddah, Saudi Arabia. \\ ${ }^{3}$ Department of Medicine, Prince Abdulaziz Bin Majed Diabetic Center, Madinah, Saudi Arabia.
}

Accepted 10 January, 2019

\begin{abstract}
Many type 1 diabetes patients (T1DM) choose to fast during Ramadan despite having an increased risk according to guidelines. Their fasting perception and practice need to be explored. The objective of this study is to examine the fasting perception and practice among T1DM patients in relation to their risk categories, metabolic conditions and in the view of practical guidelines. This cross sectional study included 113 adolescent and young Saudis with T1DM on basal bolus regimen from the diabetic center in Madinah. Data on fasting perception and practice were collected from patients 2 weeks after the end of Ramadan 2017 together with reviewing medical records. Risk categorization was performed according to Diabetes and Ramadan (DAR) 2016. The very high risk group included $78.8 \%$. Fasting was safe by $85.5 \%$, obligatory by $67.8 \%$, exempted by $2.5 \%$, and not indicated for pregnant by $6.8 \%$. Compensation for non-fasting days was obligatory by $81.4 \%$ with $16.8 \%$ used to fast extra days outside Ramadan. Among the 113 patients, $86.7 \%$ experienced fasting $(70.8 \%$ full fasters) with no significant difference in risk categories. Some patients followed the recommendations during fasting (proper meals in $26.5 \%$ at sunset , $73.5 \%$ at pre-dawn, $72.4 \%$ decreased activity, $60.1 \%$ increased fluid intake, $75.5 \%$ had inverted sleep pattern, $37.8 \%$ decreased insulin doses, $75.5 \%$ performed regular SMBG and $5.1 \%$ had professional supervision). Severe complications were $5.1 \%$ DKA and $1 \%$ severe hypoglycemia. Significant predictors for non-fasting were adolescence $(p=0.036)$, recurrent hypoglycemia $(p=0.013)$, harm perception $(p=0.006)$, non-compensation $(p=0.000)$ and comorbidities $(p=0.039)$. In conclusion, most T1DM patients chose to fast during Ramadan without adequate support or following strict guidelines. Most of them do not experience any adversities and if they break fasting (mostly due to hypoglycemia), they are able to compensate later. Adolescent patients with harm perception, recurrent hypoglycemia, and no tendency to compensate for non-fasting showed less positive attitude towards fasting. More specific guidelines, education, and professional supervision are needed for these patients during Ramadan.
\end{abstract}

Keywords: Perception, practice, type 1 diabetes, Ramadan fasting, compensation.

*Corresponding author. E-mail: inasstaha@hotmail.com.

\section{INTRODUCTION}

The practice of fasting during the month of Ramadan is a fundamental obligation in Islam but not for all Muslims. According to the Islamic law, many are exempted from fasting including pre-pubertal children and diseased patients who cannot comply with daily prolonged fasting from sunrise to sunset for a lunar month (Al-Arouj et al., 2005). Both the Islamic Organization for Medical Sciences and the International Islamic Fiqh Academy (Beshyah, 2009) and the American Diabetes Association (Al-Arouj et al., 2010) agreed to categorize all type 1 
diabetes (T1DM) patients into very high risk group and recommended against fasting based on the possible risks of severe complications. Despite all recommendations, many T1DM patients insist on fasting (Salti et al., 2004) and surprisingly studies showed that for stable T1DM with good hypoglycaemic awareness, fasting could be possible and probably safe (Kadiri et al., 2001; Benaji et al., 2006; Kobeissy et al., 2008; Beshyah et al., 2007; Kassem et al., 2005; Zabeen et al., 2014; Azad et al., 2012). Still they need pre-Ramadan medical assessment, Ramadan-focused medical education, individualized management plan, and strict medical supervision to ensure their safety (Mohsin et al., 2015; International Diabetes Federation and the DAR International Alliance, 2016). For safe fasting, the preapproach management strategy for fasting recommended 3Rs: presentation, risk stratification, and education (Hassan et al., 2014), while others recommended 5 R's: respect, risk stratification, revision of therapy, regular follow-up, and reappraisal of strategy (Jawad and Kalra, 2015). Therefore, the International Diabetes Federation (IDF), in collaboration with the Diabetes and Ramadan (DAR) International Alliance in April 2016 (IDF/DAR) stratified poorly controlled T1DM patients into the very high risk group and the wellcontrolled patients into the high risk group (International Diabetes Federation and the DAR International Alliance, 2016) and recommended against fasting in both risk groups. So, all patients with T1DM should be advised not to fast and if they have personal decisions to fast they should receive structured education, be followed by a qualified diabetes team, self-monitor blood glucose regularly (SMBG), adjust medication doses as per recommendations, be prepared to break the fast in case of hypo- or hyperglycaemia, be prepared to stop the fasting in case of frequent hypo- or hyperglycaemia or worsening consequences of other related medical conditions (International Diabetes Federation and the DAR International Alliance, 2016).

In the context of highly individualization of perception and practice of fasting, there is a need to study T1DM patients who prefer to fast during Ramadan. Therefore, this study examined the perception and practice of fasting among T1DM adolescents and young adults from Saudi Arabia in relation to their metabolic control, complications, and comorbid conditions and in comparison with the known recommendations.

\section{SUBJECTS AND METHODS}

A cross sectional study was conducted at the "Prince Abdul-Aziz Bin-Majed Diabetes Care Centre" (PAMDCC), in Madinah, Saudi Arabia. After ethical approval from the local authorities, a nonprobability convenience sample of 113 Saudis with T1DM, aged 12-35 years, on basal bolus regimen was included in the study, 2 weeks after the end of Ramadan 2017. All patients (and their parents if attended the interview) gave informed consent to participate in this study. Exclusion criteria included the presence of acute illness before Ramadan, pregnancy, chronic kidney disease stage 4 and 5 , end stage renal failure on chronic dialysis and advanced macro-vascular complications.

\section{Interview format}

Face to face interview was conducted to collect demographic and metabolic data. Questions included history of severe hypoglycemia or DKA within the 3 months period prior to Ramadan, recurrent hypoglycemia, and hypoglycemia unawareness. Questions concerning fasting practice included number of fasting days, fasting extra days during the year, causes of breaking fast and compensation for non-fasted days. Questions also included the perceived harm from fasting and fasting complications (DKA, hyperglycemia and hypoglycemia). Severe hypoglycemia was defined by any event of loss of consciousness and/or convulsion which was associated with low blood glucose ( $<60 \mathrm{mg} / \mathrm{dl}$ ), and/or responded to parenteral glucose or glucagon injection. Detailed food and fluid intake in sunset and predawn meals were recorded and revised by nutritionist to recognize both fat and carbohydrate contents and type (simple or complex) as well as food consumed between both main meals. Other lifestyle (activity and sleep pattern) and management changes (insulin doses and SMBG) during fasting were recorded.

\section{Anthropometric measurements}

Body weight was measured routinely in typical outdoor clothing without shoes using a standardized balance scale and height was measured using a stadiometer. Body mass index (BMI) was calculated as weight in $\mathrm{kg}$ divided by height squared meter. Subjects were divided into 3 groups: underweight $(<18.5)$, lean (18.5 to 24.9) and overweight ( $\geq 25$ to 29.9) and obese $(\geq 30$ $\left.\mathrm{kg} / \mathrm{m}^{2}\right)$.

\section{Review of medical records}

The files of all patients were revised for the last biochemistry, $\mathrm{HbA1c}$, presence or absence of any diabetic complications or other comorbid conditions including hypertension, thyroid disease, dyslipidemia or any other disease. Glycemic control was defined by $\mathrm{HbA} 1 \mathrm{c}<7 \%$ and dyslipidemia was defined if the latest low density lipoprotein cholesterol level was $\geq 2.6 \mathrm{mmol} / \mathrm{L}$.

\section{Risk categorization}

Risk categorization was performed according to the practical guidelines of the IDF-DAR in 2016 (International Diabetes Federation and the DAR International Alliance, 2016). The very high risk group included T1DM patients with any one or more of the following: severe hypoglycaemia within the 3 months period prior to Ramadan, DKA within the 3 months period prior to Ramadan, history of recurrent hypoglycemia, history of hypoglycemia unawareness, or poorly controlled. The high risk group included well controlled T1DM patients who did not have any criteria of the very high risk category.

\section{Statistical analysis}

Data analysis was performed by Statistical Package for the Social Sciences program version 20. 0 Data with abnormal distribution were expressed in median. $\mathrm{P}<0.05$ was considered to be the cutoff value of significance. Statistical analysis was performed using 
the non-parametric test for comparing the 3 fasting groups. Odd ratios were calculated through the multinomial logistic regression analysis.

\section{RESULTS}

A total of 113 Saudi patients aged 12 to 35 years were included in this study, $55.8 \%$ of them being females. Their average age was 19 years, $53.1 \%$ were adolescents, $46.9 \%$ were young adults, and $46.9 \%$ had diabetes for $>5$ years. Only $11.5 \%$ of patients were employed, the remaining was either students $(68.1 \%)$ or non-workers (20.4\%). None of the employed patients was engaged in intense physical activity. Their average BMI was $23.26 \mathrm{~kg} / \mathrm{m}^{2}$ with $18.5 \%$ underweight, $66.2 \%$ lean, $6.2 \%$ overweight and $9.2 \%$ obese. Their average A1C was high $(9.9 \%)$ with $83.3 \%$ of patients were uncontrolled. Among the patients $7.1 \%$ were smokers, $7.1 \%$ had hypertension, $16.8 \%$ had thyroid diseases, and $23.9 \%$ were dyslipidemic (Table 1 ).

Table 1 shows also that many cases $(74.3 \%)$ were poorly controlled. Within the 3 months period prior to Ramadan, 11 patients were reported to have DKA $(9.7 \%)$ and 4 patients $(3.5 \%)$ were reported to have severe hypoglycemia. Many patients (33.8\%) had history of recurrent mild to moderate hypoglycemia but only 2 patients (1.8\%) with hypoglycemia unawareness. However, none was reported to have non-compliance to insulin therapy, or recurrent hospitalizations. Other criteria for risk stratification of IDF/DAR were excluded on selection of cases. The very high risk group included $78.8 \%$ of all patients and the remaining $21.2 \%$ of the cases were in the high risk group. Most patients (85.5\%) perceived no harm with fasting. Many T1D patients $(67.8 \%)$ believed that they are not exempted from fasting and they should fast (obligation), while few believe that they are exempted (2.5\%). Pregnancy was a cause for exemption by $6.8 \%$ of patients. Most of the patients admitted that they considered compensation for non-fasting days as obligatory (81.4\%). Moreover, some $(16.8 \%)$ used to fast extra-days outside Ramadan (Table 2).

The patients were divided into 3 groups according to their fasting practice during Ramadan 2017. Fasting was practiced by most patients (86.7\%) and only 15 patients $(13.3 \%)$ did not fast. Most of them (70.8\%) fasted for $>20$ days. Concerning lifestyle changes, following dietary recommendation, $26.5 \%$ did not consume excess carbohydrate and fat at the sunset meal, $73.5 \%$ consumed complex carbohydrate at the pre-dawn meal, $72.4 \%$ decreased their activity during fasting hours, many did not increase their carbohydrate amount (49\%), sweets intake $(59 \%)$ or food intake $(70.4 \%)$ throughout the day, $60.1 \%$ increased their fluid intake and many patients (75.5\%) had reversed sleep pattern. Concerning their management changes, $37.8 \%$ decreased their insulin dose, $75.5 \%$ performed regular
SMBG and $5.1 \%$ received professional supervision. Most of them (94.9\%) were reported to have usual diabetes care with no extra-appointments during Ramadan in clinics (Table 3).

Among fasting patients, many experienced no complications (53.1\%), 19.4\% hyperglycemia and 37.8\% mild to moderate hypoglycemia. Severe complications were reported by 6 patients $(5(5.1 \%)$ with DKA and one with severe hypoglycemia (1\%)). Hypoglycemia (14.4\%); rather than hyperglycemia (1\%) or fatigue and dizziness $(1 \%)$, was the main cause of immediate breaking of fasting (Table 3).

Comparison between the 3 fasting groups showed that non-fasting group was significantly adolescents $(p=$ $0.002)$, underbuilt/lean $(p=0.029)$, higher perception of harm $(p=0.001)$ and lower tendency to compensate for non-fasting days $(p=0.000)$ than the other 2 groups. There was no significant difference in the risk stratification among the 3 groups $(p=0.603)$, however, the non-fasting group had a higher history of recurrent hypoglycemia $(p=0.006)$. Concerning the lifestyle and management changes, there was no difference between the 2 fasting groups except for more compensation in the group of fasting $>20$ days $(95.2 \%)$ than the other fasting group $(66.7 \%)(p=0.000)$. Full fasters showed more frequent inverted sleep rhythm $(p=0.023)$ and hyperglycemia $(p=0.027)$, but lower hypoglycemia $(p=$ 0.005 ) than those who fasted less than 20 days (Table 4).

Significant predictors for non-fasting were adolescence ( $p=0.036)$, recurrent hypoglycemia ( $p=$ $0.013)$, harm perception ( $p=0.006)$, non-compensation $(p=0.000)$ and comorbidities $(p=0.039)$. Significant predictors for incomplete fasting were adolescence $(p=$ $0.04)$ and non-compensation ( $p=0.015)$ (Table 5).

\section{DISCUSSION}

It has been seen in this study that most of the included T1DM patients $(78.7 \%)$ were in the category of the very high risk, who need to be exempted from fasting and should receive education and training with strict follow up in attempt of fasting during Ramadan (International Diabetes Federation and the DAR International Alliance, 2016). However, some might choose to fast (86.7\%) and some $(16.8 \%)$ practiced fasting of extra-days for other religious occasions. T1DM patients in this study considered Ramadan fasting as safe (85.5\%) and obligatory $(67.8 \%)$. Therefore, they believe that they should not terminate fasting for any cause and should compensate for non-fasting days (81.4\%). The reported fasting complications in this study were mild $(41.6 \%)$ with few DKA $(4.4 \%)$ or severe hypoglycemia $(0.9 \%)$ for circulation for more than $8 \mathrm{~h}$ (Karamat et al., 2010). Generally, lifestyle and management recommendations during Ramadan were not well applied by most of them 
Table 1. Demographic and metabolic characteristics of type 1 diabetes patients $(n=113)$.

\begin{tabular}{|c|c|c|c|}
\hline \multirow{2}{*}{ Variable } & & \multicolumn{2}{|c|}{ Frequency } \\
\hline & & $\mathbf{N}$ & $\%$ \\
\hline \multirow{2}{*}{ Age groups } & Adolescent & 60 & 53.1 \\
\hline & Young adults & 53 & 46.9 \\
\hline \multirow{2}{*}{ Duration of diabetes } & $\leq 5$ years & 60 & 53.1 \\
\hline & $>5$ years & 53 & 46.9 \\
\hline \multirow{2}{*}{ Gender } & Female & 63 & 55.8 \\
\hline & Male & 50 & 44.2 \\
\hline \multirow{3}{*}{ Occupation } & Students & 77 & 68.1 \\
\hline & Not working & 23 & 20.4 \\
\hline & Employed & 13 & 11.5 \\
\hline \multirow{4}{*}{ Weight groups } & Underweight & 21 & 18.5 \\
\hline & Lean & 75 & 66.2 \\
\hline & Overweight & 7 & 6.2 \\
\hline & Obese & 10 & 9.2 \\
\hline \multirow{3}{*}{ Micro-vascular complications } & Neuropathy & 23 & 20.4 \\
\hline & Nephropathy & 5 & 4.4 \\
\hline & Retinopathy & 10 & 8.8 \\
\hline \multirow{6}{*}{ Other comorbidities } & Smoking & 8 & 7.1 \\
\hline & Hypertension & 8 & 7.1 \\
\hline & Thyroid disease & 19 & 16.8 \\
\hline & Dyslipidemia & 27 & 23.9 \\
\hline & Others & 11 & 9.3 \\
\hline & Total comorbidities & 41 & 36.3 \\
\hline
\end{tabular}

Table 2. Perception of Ramadan fasting by type 1 diabetes patients $(n=113)$.

\begin{tabular}{|c|c|c|c|}
\hline \multirow{2}{*}{ Variable } & & \multicolumn{2}{|c|}{ Frequency } \\
\hline & & $\mathbf{N}$ & $\%$ \\
\hline \multirow{2}{*}{ Harm perception from fasting } & No harm & 97 & 85.5 \\
\hline & Harm & 16 & 14.2 \\
\hline \multirow{3}{*}{ Causes of exemption from fasting } & No exemption (fasting is an obligation) & 80 & 67.8 \\
\hline & Type 1 patients & 3 & 2.5 \\
\hline & Pregnancy & 8 & 6.8 \\
\hline \multirow{2}{*}{ Compensation for non-fasting days } & Not obligatory & 21 & 18.6 \\
\hline & Obligatory & 92 & 81.4 \\
\hline Fasting extra days outside Ramadan & & 19 & 16.8 \\
\hline
\end{tabular}

and only $5.1 \%$ received professional observation while fasting.

These results were not in agreement with those of the
EPIDIAR study, where $43 \%$ used to fast with 4.7 -fold increase in the risk of severe hypoglycemia (Salti et al., 2004). Moreover, one Saudi study (Salman et al., 1992) 
Table 3. Complications during Ramadan fasting in type 1 diabetes patients $(n=98)$.

\begin{tabular}{llc}
\hline Variable & Frequency (\%) \\
\hline No complications & $52(53.1)$ \\
DKA & & $5(5.1)$ \\
Hyperglycemia & $19(19.4)$ \\
& & \\
Hypoglycemia & Mild-moderate hypoglycemia & $37(37.8)$ \\
& Severe hypoglycemia & $1(1.02)$ \\
& & \\
Causes of immediate break fasting. & Hypoglycemia & $14(14.3)$ \\
& Hyperglycemia & $1(1)$ \\
& & $1(1)$ \\
\hline
\end{tabular}

Table 4. Significant differences between different fasting groups of type 1 diabetes $(n=113)$.

\begin{tabular}{|c|c|c|c|c|c|}
\hline & & $\begin{array}{c}\text { Not fasting } \\
\mathrm{N}=15(13.3 \%)\end{array}$ & $\begin{array}{c}\text { Fasting }<20 \text { days } \\
\mathrm{N}=18(15.9 \%)\end{array}$ & $\begin{array}{c}\text { Fasting }>\mathbf{2 0} \text { days } \\
\mathrm{N}=\mathbf{8 0}(\mathbf{7 0 . 8 \% )}\end{array}$ & $\mathbf{P}$ \\
\hline \multicolumn{6}{|l|}{ Characteristics } \\
\hline \multirow{2}{*}{ Age groups } & Adolescent & $11(73.3 \%)$ & $15(83.3 \%)$ & $34(42.5 \%)$ & \multirow{2}{*}{0.002} \\
\hline & Young adults & $4(26.7 \%)$ & $3(16.7 \%)$ & $46(57.5 \%)$ & \\
\hline \multirow{4}{*}{ Weight groups } & Underbuilt & 7 (46.7\%) & $7(38.9 \%)$ & $7(8.75 \%)$ & \multirow{4}{*}{0.029} \\
\hline & Lean & $8(53.3 \%)$ & $9(50.0 \%)$ & $58(72.5 \%)$ & \\
\hline & Overweight & $0(0 \%)$ & $0(0 \%)$ & $7(8.75 \%)$ & \\
\hline & Obese & $(0 \%)$ & $2(11.1 \%)$ & $8(10 \%)$ & \\
\hline \multicolumn{6}{|l|}{ Risk categorizations } \\
\hline \multirow{3}{*}{ Risk category } & Very high risk & $11(73.3 \%)$ & $13(72.2 \%)$ & $65(81.3 \%)$ & \multirow{2}{*}{0.603} \\
\hline & High risk & $4(26.7 \%)$ & $5(27.8 \%$ & $15(18.8 \%)$ & \\
\hline & Recurrent hypoglycemia & $9(60.0 \%)$ & $2(11.1 \%)$ & $16(20 \%)$ & 0.006 \\
\hline \multicolumn{6}{|l|}{ Perception } \\
\hline \multirow{2}{*}{\multicolumn{2}{|c|}{$\begin{array}{l}\text { Harm perception } \\
\text { Compensation for non-fasting }\end{array}$}} & $6(40.0 \%)$ & $2(11.1 \%)$ & $8(10.0 \%)$ & 0.001 \\
\hline & & $1(6.7 \%)$ & $14(77.8 \%)$ & 77 (96.3\%) & 0.000 \\
\hline \multicolumn{6}{|l|}{ Practice of fasting } \\
\hline Lifestyle changes & Inverted sleep rhythm & & $6(30 \%)$ & 57 (71.25\%) & 0.023 \\
\hline \multirow{2}{*}{$\begin{array}{l}\text { Complications during } \\
\text { fasting }\end{array}$} & Hypoglycemia* & & $11(61.1 \%)$ & $26(32.5 \%)$ & 0.005 \\
\hline & Hyperglycemia & & $1(5.6 \%)$ & $18(22.5 \%)$ & 0.027 \\
\hline
\end{tabular}

*Mild to moderate.

Table 5. Significant predictors for non-fasting or incomplete fating rather than full fasting among type 1 diabetic patients $(n=113)$.

\begin{tabular}{|c|c|c|c|c|c|c|c|c|}
\hline \multirow{3}{*}{$\begin{array}{l}\text { Variable } \\
\text { Adolescence }\end{array}$} & \multicolumn{4}{|c|}{ Non-fasting Ramadan } & \multicolumn{4}{|c|}{ Fasting $<20$ days } \\
\hline & \multirow{2}{*}{$\begin{array}{l}\text { OR } \\
3.72\end{array}$} & \multicolumn{2}{|c|}{$95 \% \mathrm{Cl}$} & \multirow{2}{*}{\begin{tabular}{c|}
$\mathbf{P}$ \\
0.036
\end{tabular}} & \multirow{2}{*}{$\frac{\text { OR }}{6.77}$} & \multicolumn{2}{|c|}{$95 \% \mathrm{Cl}$} & \multirow{2}{*}{$\frac{\mathbf{P}}{0.004}$} \\
\hline & & 1.09 & 12.69 & & & 1.813 & 25.23 & \\
\hline Recurrent hypoglycemia & 7.18 & 1.52 & 33.92 & 0.013 & 0.32 & .096 & 1.04 & 0.059 \\
\hline Perception of harm & 6.00 & 1.69 & 21.26 & 0.006 & 1.13 & 0.22 & 5.81 & 0.888 \\
\hline Non-compensation & 359.3 & 34.83 & 3706.95 & 0.000 & 7.3 & 1.478 & 36.38 & 0.015 \\
\hline Comorbidities & 3.30 & 1.06 & 10.28 & 0.039 & 1.40 & 0.486 & 4.04 & 0.533 \\
\hline
\end{tabular}

Reference category: Fasting $>20$ days.

OR: odd ratio, Cl: Confidence Interval. 
from Riyadh reported three T1DM children with severe hypoglycemia within the 1st week of fasting. However, the reported incidence of hypoglycemia in our results $(37.8 \%)$ was in agreement with another multi-centered prospective study from Pakistan (35.3\%) (Ahmedani et al., 2014). One study involved 33 adolescent children with T1DM under strict training and follow up, found that $60.6 \%$ completed the fast with only five cases of mild hypo-glycaemia and no cases of DKA were reported (Azad et al., 2012). In our study, a much higher frequency $(70.8 \%)$ had completed their fasting but without adequate fasting plans or supervision.

The low incidence of severe hypoglycemia in the present study could be explained by the patients' high $\mathrm{HbA1c}$, increased sweet intake, decreased activity, decreased insulin dose and inverted sleep rhythm which made them more vulnerable to DKA rather than severe hypoglycemia, but did not protect them from exposing to mild hypoglycemia upon fasting. In support of our findings, Reiter et al. (2007) reported that $65 \%$ of their T1DM patients successfully fasted without harm which was probably because of their higher $\mathrm{HbA} 1 \mathrm{c}$ levels, high adherence to the protocol, and reductions in insulin dosage. Another explanation given was that all patients were on basal bolus therapy using insulin analogous preparations which were presumed to have lower incidence of hypoglycemia than human soluble insulin that may remain in the circulation.

A substantial number of the patients included were under the very high risk group $(78.8 \%)$ based on poor diabetes control $(74.3 \%)$, history of preceding severe hypoglycemia $(3.5 \%)$, or DKA $(9.7 \%)$, recurrent hypoglycemia $(33.8 \%)$ and hypoglycemia unawareness $(1.8 \%)$. But, only the history of recurrent hypoglycemia showed influence on the decision not to fast $(p=0.013)$. Adolescence predicted both non-fasting $(p=0.036)$ and inability to complete fasting $(p=0.004)$. In accordance with the Islamic law where adolescents are obliged to fast, adolescents in this study were more likely than young adults to go for not fasting (OR 3.72) or fasting less than 20 days (OR 6.77) than full fasting. Previous studies documented the safety of fasting in children and adolescents with well-structured program of education for both children and their families prior to Ramadan together with close follow-up (Kadiri et al., 2001; Kobeissy et al., 2008; Kassem et al., 2005; Zabeen et al., 2014; Azad et al., 2012; Ahmedani et al., 2014; Reiter et al., 2007).

Other predictors of non-fasting included the belief of harm induced by fasting and the absence of an obligation to compensate for non-fasting by fasting equal number of days after Ramadan $(p=0.015)$ (Table 5). Our T1D patients who believed in necessary compensation (81.4\%) may prefer to fast during Ramadan with their families rather than fasting alone later on. This is in contrast to the Islamic regulations, which entails no compensation for patients with chronic illnesses. It is expected that T1D patients will not put themselves at risk and they will break their fasting easily for any danger, simply if they know and follow proper Islamic regulation.

In this study, a substantial number of patients followed guidelines as consuming complex carbohydrates at the pre-dawn meal, decreasing activity with inverted sleep cycle, increasing fluid intake, decreasing insulin dose, and performing SMBG. However, some weak points in the practice of fasting by those patients deserve attention. First; only $37.8 \%$ decreased their insulin doses during Ramadan fasting. Second; many (73.5\%) used to ingest large amounts of foods rich in carbohydrates and fats at the sunset meal. Third; only $14.4 \%$ used to immediately end their fast if hypoglycemia occurs, and very few used to do so if blood glucose exceeds 300 $\mathrm{mg} / \mathrm{dl}$. Forth; very few patients received professional supervision while fasting and the majority of the patients did not receive any extra-care before or during fasting. All these defective points should be emphasized in the future management plans for better management of T1DM during fasting.

\section{Limitations}

The main limitation of this study was its cross sectional design which did not allow for extracting strong evidence about perception of fasting by T1DM patients. Moreover, all data were self-reported and documentation was lacking especially for fasting-related complications.

\section{CONCLUSION AND RECOMMENDATIONS}

Most patients with T1DM chose to fast during the month of Ramadan, and they do so without adequate support or following strict guidelines. Most of them do not experience any adversities during fasting and if they break fasting (mostly due to hypoglycemia), they are able to compensate later. Adolescent patients with harm perception, history of recurrent hypoglycemia, comorbidities, and who belief in non-compensation, showed less positive attitude towards fasting. Many of the perception and practice of these patients did not follow Islamic regulations. Therefore, there is an urgent need for better designed large clinical trials which could find evidence-based information concerned with safety and how best we should manage patients with T1DM fasting Ramadan. Such information is necessary for developing solid guidelines to assist patients who want to fast on any religious occasions. Meanwhile, health care professionals should ensure adequate education of their patients about their fasting rights in Islam. They should perform a systematic pre-Ramadan assessment with appropriate therapeutic adjustments and educational advice regarding healthy diet, exercise and 
awareness of the risks of hypo- and hyper-glycemia. They should ensure regular follow-up in clinics and might involve parental supervision when appropriate.

\section{REFERENCES}

Ahmedani MY, Alvi SF, Haque MS, Fawwad A, Basit A, 2014. Implementation of Ramadan-specific diabetes management recommendations: a multi-centered prospective study from Pakistan. J Diab Metab Disord; 13: 37.

Al-Arouj M, Assaad-Khalil S, Buse J, Fahdil I, Fahmy M, Hafez S, Hassanein M, Ibrahim MA, Kendall D, Kishawi S, Al-Madani A, Nakhi AB, Tayeb K, Thomas A, 2010. Recommendations for management of diabetes during Ramadan: Update 2010. Diab Care, 33: 1895-1902.

Al-Arouj M, Bouguerra R, Buse J, Hafez S, Hassanein M, Ibrahim MA, Ismail-Beigi $F$, El-Kebbi I, Khatib O, Kishawi S, Al-Madani A, Mishal AA, Al-Maskari M, Nakhi AB, Al-Rubean K, 2005. Recommendations for management of diabetes during Ramadan. Diab Care, 28: 2305-2311.

Azad K, Mohsin F, Zargar AH, Zabeen B, Ahmad J, Raza SA, Tayyeb S, Bajaj S, Ishtiaq O, Kalra S, 2012. Fasting guidelines for diabetic children and adolescents. Indian J Endocrinol Metab, 16: 516-518.

Benaji B, Mounib N, Roky R, Aadil N, Houti IE, Moussamih S, Maliki S, Gressier B, El Ghomari H, 2006. Diabetes and Ramadan: Review of the literature. Diab Res Clin Pract, 73: 117-125.

Beshyah S, Benbarka M, Sherif I, 2007. Practical management of diabetes during Ramadan Fast. Libyan J Med, 2: 185-189.

Beshyah SA, 2009. Fasting during the month of Ramadan for people with diabetes: Medicine and Fiqh united at last. Ibnosina $\mathrm{J}$ Med Biomed Sci, 1: 58-60.

Hassan A, Meo SA, Usmani AM, Shaikh TJ, 2014. Diabetes during Ramadan - PRE-approach model: presentation, risk stratification, education. Eur Rev Med Pharmacol Sci, 18: 1798-805.

International Diabetes Federation and the DAR International Alliance, 2016. Diabetes and Ramadan: Practical Guidelines. Brussels, Belgium: International Diabetes Federation. www.idf.org/guidelines/diabetes-in-ramadan and www.daralliance .org.

Jawad F, Kalra S, 2015. Ramadan and diabetes management - The 5 R's. J Pak Med Assoc, 65: S79-S80.

Kadiri A, Al-Nakhi A, El-Ghazali S, Jabbar A, Al Arouj M, Akram J, Wyatt J, Assem A, Ristic S, 2001. Treatment of type 1 diabetes with insulin lispro during Ramadan. Diab Metab, 27: 482-486.

Karamat MA, Syed A, Hanif W, 2010. Review of diabetes management and guidelines during Ramadan. J R Soc Med, 103: 139-147.

Kassem HS, Zantout MS, Azar ST, 2005. Insulin therapy during Ramadan fast for Type 1 diabetes patients. J Endocrinol Invest, 28: 802-805.

Kobeissy A, Zantout MS, Azar ST, 2008. Suggested insulin regimens for patients with type 1 diabetes mellitus who wish to fast during the month of Ramadan. Clin Ther, 30: 1408-1415.

Mohsin F, Azad K, Zabeen B, Tayyeb S, Baki A, Nahar N, 2015. Should Type 1 diabetics fast in Ramadan. J Pak Med Assoc, 65: S26-S29.
Reiter J, Wexler ID, Shehadeh N, Tzur A, Zangen D, 2007. Type 1 diabetes and prolonged fasting. Diab Med, 24(4): 436-439.

Salman H, Abdallah MA, Abanamy MA, al Howasi M, 1992. Ramadan fasting in diabetic children in Riyadh. Diabet Med, 9: 583-584.

Salti I, Bénard E, Detournay B, Bianchi-Biscay M, Le Brigand C, Voinet C, Jabbar A; EPIDIAR study group, 2004. A populationbased study of diabetes and its characteristics during the fasting month of Ramadan in 13 countries: Results of the epidemiology of diabetes and Ramadan 1422/2001 (EPIDIAR) study. Diab Care, 27: 2306-2311.

Zabeen B, Tayyeb S, Benarjee B, Baki A, Nahar J, Mohsin F, Nahar $\mathrm{N}$, Azad K, 2014. Fasting during Ramadan in adolescents with diabetes. Indian J Endocrinol Metab, 18(1): 44-47.
Citation: Taha I, Sultan I, Al-Harby A, Alharizi R, Ghandoura L, 2019. Perception and practice of Ramadan fasting among patients with type I diabetes mellitus in the view of the practical guidelines. Int ResJ Med Med Sci, 7(1): 21-27. 